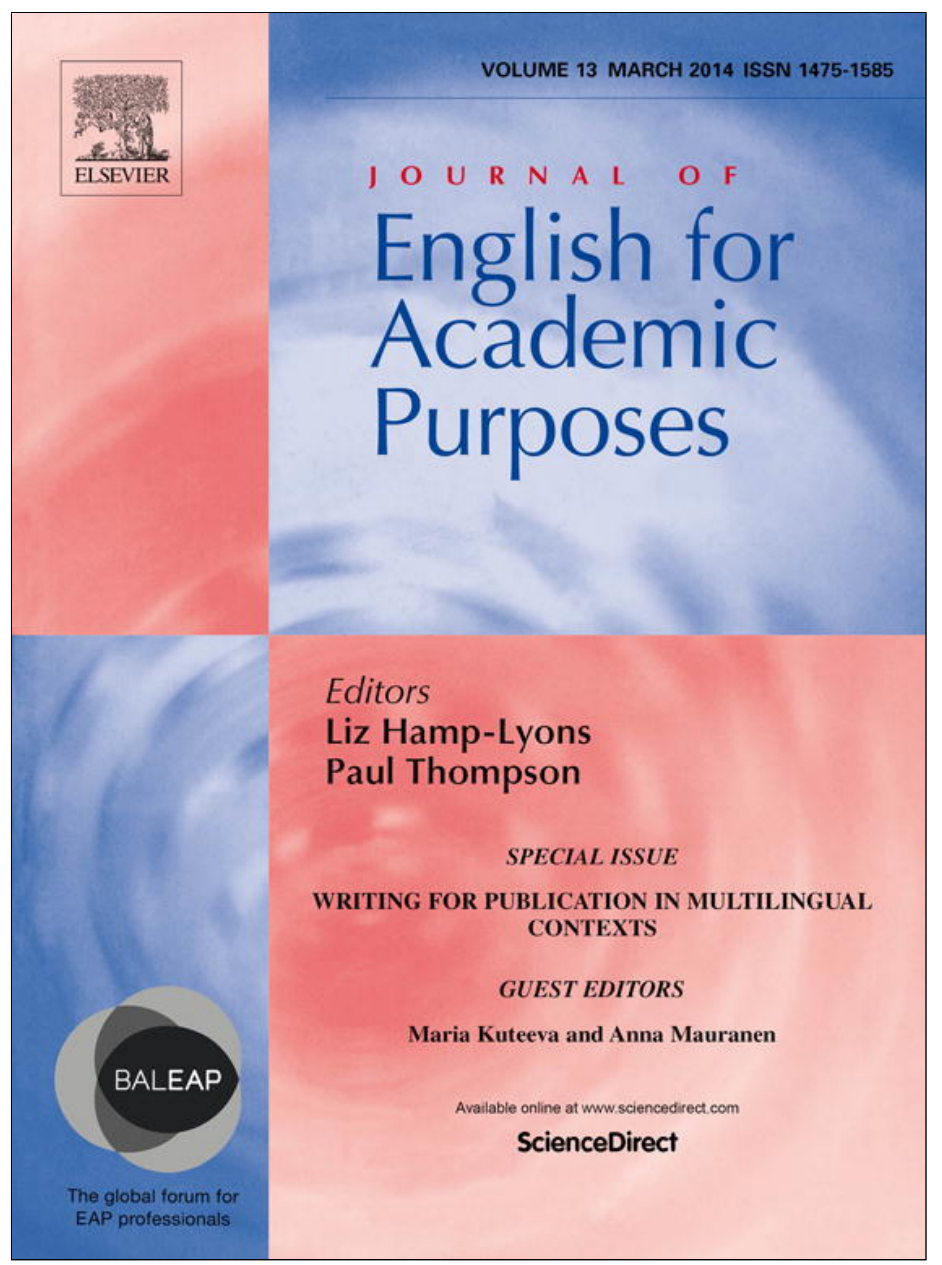

This article appeared in a journal published by Elsevier. The attached copy is furnished to the author for internal non-commercial research and education use, including for instruction at the authors institution and sharing with colleagues.

Other uses, including reproduction and distribution, or selling or licensing copies, or posting to personal, institutional or third party websites are prohibited.

In most cases authors are permitted to post their version of the article (e.g. in Word or Tex form) to their personal website or institutional repository. Authors requiring further information regarding Elsevier's archiving and manuscript policies are encouraged to visit: 
Forum

\title{
Writing and publishing in peripheral scholarly journals: How to enhance the global influence of multilingual scholars?
}

\author{
Françoise Salager-Meyer* \\ Graduate School of Medicine, Universidad de Los Andes, Apartado 715, Mérida 5101, Venezuela
}

Keywords:

Periphery

Center

Scientific publication

Multilingual scholar

Domestic journals

National languages

\begin{abstract}
A B S T R A C T
I begin this opinion piece by defining the two main sets of scientific publications, viz., mainstream/center journals and peripheral/small ones. I then analyze why multilingual peripheral scholars choose to publish their research results in English-medium journals and why they also often choose to publish them in domestic journals written in national languages. Because of the existing highly competitive journal publishing environment, I present a few measures that could be undertaken to allow multilingual peripheral researchers to increase their influence as global partners in the world of science.
\end{abstract}

(c) 2013 Elsevier Ltd. All rights reserved.

Science - used here in its Latin-based meaning 'scientia' as knowledge making across the full spectrum of scholarly disciplines from the natural sciences to the humanities - is increasingly global today. However, it remains concentrated. According to the Royal Society Report (2011) based on data drawn from Elsevier's Scopus database, ${ }^{1}$ the traditional "scientific superpowers" still lead the field in flagship universities and institutes in the USA, Western Europe and Japan. However, the emergence of new players - not only Brazil, Russia, India, China and South Korea, but also in the Middle East, South East Asia and North Africa - points towards an increasingly multipolar scientific world in which the distribution of scientific activity is concentrated in a number of interconnected and widely dispersed hubs. China, for example, overtook Japan and Europe in terms of its publication output in recent years to the point that it is now the second producer of scholarly paper output in the world, the first position being held by the USA (Royal Society Report, 2011).

In this new scientific landscape, national languages are playing an increasingly important role in many countries where academic reward systems take into consideration publications in domestic journals. Indeed, multilingual scholars across disciplines often resort to both English and national languages to facilitate national scholarly exchange of ideas and new knowledge dissemination (see, for example, Li, in press).

In this opinion piece, I will first define the two main sets of scholarly publications and explain the reasons why multilingual peripheral scholars often choose to publish their research findings in domestic journals written in their native language. I will then propose a few measures that could be undertaken for these journals to play a more prominent role as global partners in the international scientific community.

\section{Academic publishing: a hierarchical and competitive system}

Competition rules in the world of academic publishing, and scholarly publications embody a great deal of power. They structure academic careers almost all over the world and in almost all disciplines. According to Guédon (2010), scholarly

\footnotetext{
* Tel./fax: +58 2742660289, +58 4162751932 (Mobile).

E-mail address: francoise.sm@gmail.com.

1 Scopus is the world's largest abstract and citation database of peer-reviewed literature. It contains over 41 million records across 18,000 journals in all disciplines and covers regional as well as international literature.
} 
journals fall into two categories divided by a wide gap: the first is made up of "mainstream" journals that originate in industrialized (also called "center") countries, and the second consists of "small/peripheral" periodicals emanating from developing/peripheral countries and/or emerging research centers. I shall briefly define each group.

\subsection{Mainstream/center publications}

The first group of publications is either referred to as "mainstream", “center", "high-ranking” or "elite” (Guédon, 2010; Salager-Meyer, 2008) These are indexed in the Science Citation Index, the Social Science Citation Index or the Arts and Humanities Citation Index, all published by Thomson Reuters. They are written in English, a language that, as Lillis and Curry (2013: 221) aptly put, "is not just the language of science but rather the language of the richer countries at the heart of scientific production and the language of the most prestigious journals". The pressure to publish in these peer-reviewed elite outlets has grown tremendously worldwide over the past thirty years or so, and has been amply documented in research on English as an Additional Language (e.g. Harzing, 2013; Martínez, 2011). Although this emphasis on publishing in high-ranking English-medium journals may ease communication among scientists, it also creates problems for non-English-speaking countries because even if these countries' scientists are able to read scientific articles written in English, they must still translate this knowledge into a national context.

\subsection{Domestic peripheral journals}

The second set of scholarly periodicals is generally referred to as "peripheral" or "small journals" (Canagarajah, 2002; Davis \& Eisemon, 1989; Guédon, 2010; Salager-Meyer, 2008; Stegemann, 2007). The expression "small journals" has nothing to do with size or print run, but refers to those journals published in peripheral countries that are mainly absent from international databases (Guédon, 2010; Stegemann, 2007), such as the Science Citation Index, The Social Science Citation Index or their equivalents. Except in developing countries where the national language is English, these peripheral journals are mostly written in the researchers' native language (e.g. Spanish, Portuguese, Chinese, Russian, Farsi, etc). However, in the search for better international visibility, and, as a consequence, of a wider international readership, some peripheral journals in Mexico, Russia, Serbia, Iran, South Korea and Brazil have switched to English (Kosanović, 2013; Lillis \& Curry, 2013), while others have turned bilingual, i.e. they provide the full text English translation of the papers they publish.

Because over $85 \%$ of the world's population lives in the 153 countries categorized as low- and/or middle-income countries, we can easily assert that there is a world of publishing that does not operate in English or emanate from English-speaking countries.

\section{The multilingual peripheral scholar's publishing in L1 and in English}

Non-native English researchers face multifarious difficulties when writing their articles in English for their possible publication in mainstream journals. These difficulties have been extensively documented in the literature and are mainly language/discourse-related, such as a low level of basic academic writing skills, including rhetorical and argumentative skills (see, for example, Curry \& Lillis, 2004; Ferguson, Pérez Llantada, \& Plo, 2011; Flowerdew, 2013; Lillis \& Curry, 2010). But in the specific case of non-native English speakers from developing countries, non-linguistic/discursive difficulties (e.g. poor infrastructure, sporadic and intermittent internet connectivity, electricity outages, scarce or non-existent material and/or bibliographical resources, low wages, etc.) add to the linguistic hurdles (see, for instance, Canagarajah, 1996, 2002; Englander, 2011; Salager-Meyer, 2008; Uzuner, 2008).

Non-native English speaking scholars are often required to invest vast resources of time and money to produce manuscripts that fulfill the expectations of these mainstream journal reviewers, board members and editors who are quite frequently based in high-income countries and have a good to excellent mastery of English (Harzing \& Metz, 2012; Lown \& Banerjee, 2006; Salager-Meyer, 2008). Moreover, many of these non-native English-speaking scholars grow frustrated by the high rejection rate of their papers submitted to elite journals (Coates, Sturgeon, Bohannan, \& Pasini, 2002; Mur Dueñas, 2012; Shashok, 2008; Uzuner, 2008). However, the role of publishing in developing countries cannot be ignored. As Johns (2013: 18) reports, specifically referring to the English for Specific Purposes field (ESP), "there is much more happening in ESP than one would assume from examining international journals". In spite of the generalized pressure to publish research outcomes in English-medium journals, scientists who live, work and write in peripheral countries often choose to publish their research results in domestic journals.

Indeed, because of the above-mentioned discursive and non-discursive barriers, "small journals" provide many scholars from Africa, Asia, Latin America, the Middle East, and Central and Eastern Europe with a platform for disseminating their work in their national languages to their national and regional scientific community. For example, Li (in press) interviewed a group of medical researchers from major teaching hospitals in China and reports that a majority of them choose to write in English because, for these hospital heads of departments, English-written papers count much more than Chinese-written papers, leading to both material and symbolic rewards. This corroborates the findings of previous research on multilingual researchers (e.g. Caramelli \& Rocha e Silva, 2010; Flowerdew \& Li, 2009; Li \& Flowerdew, 2009; Petersen \& Shaw, 2002; Shen, Jiang, \& Zheng, 2010), also called “double agents" (Yanos \& Ziedonis, 2006: 249), which disclosed that these scholars prefer to 
submit their most original, scientifically robust and ground-breaking papers (whether in pure research or in practitioneroriented journals) to English-written journals with a high impact factor.

Some of Li's (in press) interviewees, however, also publish in Chinese in order to report their research results to the Chinese-speaking academic community and exchange their views with its members. In other words, the reason why some Chinese and other peripheral researchers publish in domestic journals is not simply for convenience but because they wish to engage in local research activities and reach their immediate (local) target readership who generally do not read Englishwritten papers. As a consequence, publishing in domestic journals helps them not only to exchange ideas with national/ regional colleagues but also to spread their names in their national communities of practice.

Another powerful reason for publishing in national peripheral journals is that these journals allow local staff to achieve career promotion. Indeed, most of them are owned, funded and published by universities (the government sector), and they usually publish articles written by the academic staff of the publishing university (Guédon, 2010; Li, in press; Salager-Meyer, 2008). Referring to the national journals situation in Iran, Habibzadeh (2006b) argues that the major role of these local journals is to help the academic staff to get published to earn tenure and promotion. This opinion is echoed by Beall (2012) and Balaram (2013) about scholarly publishing in India and its neighboring countries, and by Duszak (2006) and Kosanović (2013) regarding the publications of books in the humanities and social sciences in Poland and Serbia.

The problem is that the quality of these "non-international" journals - that are frequently perceived as having a low level of challenge - has been questioned in a variety of geographical contexts. It is therefore urgent to improve their status so that they can contribute to the enhancement of universal knowledge and act as partners in the international scientific community. I hereafter propose a few measures that could be undertaken towards that goal.

\section{Peripheral journals as scholarly partners: from locality to globality}

\subsection{Journal quality and unification}

Instead of each department, school or postgraduate program at a university or each professional association having its own publications, peripheral journals could be co-published by national or regional professional associations with closely related scope of interests. Such a step would involve sharing publication costs and creating joint editorial boards. In other words, the editors of journals within the same field/with the same interest/addressing the same readership should discuss the unification of their representative journals so as to publish one journal only that would attract high-quality papers. Regular publication of a much lesser number of journals could then be achieved because the cost of publication would be reduced.

To increase the visibility of peripheral journals published in languages other than English, i.e. to upgrade them from the local to a global status, the solution, then, is not to launch more and more journals, but, on the contrary, to reduce their number and encourage researchers to publish in them. Journal editors should then ensure that the papers published are of excellent quality to allow their journals to attract stellar research written not only by national researchers (authors and readers) but also by foreign ones. Governmental agencies have their role to play too: they should provide adequate financial support and be aware that the strength of their national publications is important for the scientific growth and development of their country.

\subsection{Websites and indexation}

Editorial departments should also establish websites with excellent search functions, full text retrieval, and an onlinereading system so that the papers published in these journals can be rapidly disseminated and fully exchanged. Better still, these websites could provide information in English that would help increase the journal influence. Apart from the initial costs of posting the material on a website, increasing online availability is cost effective since little additional expenditure is required to provide access to new users. These online versions of journals should be regularly updated to meet the everdemanding criteria of major indexing organizations, such as the quality of the journal's scientific guidelines, its publishing board, periodicity, punctuality, and number of articles published in a year. I am not only referring here to the Science Citation Index or the Social Science Citation Index, but also to such regional indexing systems as Index Copernicus (Eastern Europe), LATINDEX (Regional Cooperative Online Information System for Scholarly Journals from Latin America, the Caribbean, Spain and Portugal), LILACS (index of scientific and technical literature of Latin America and the Caribbean), REDALYC (Latin American, Caribbean, Spanish and Portuguese Scientific Journals Network), SciELO (Scientific Electronic Library on Line) whose aim is to promote free electronic publishing journals from developing countries.

Regardless of the database used, editors and publishers should give proper indexing a high priority because an inappropriate indexing can make it very difficult for researchers to locate a specific journal or article.

\subsection{Research integrity: journal adherence to international guidelines}

Adherence to the basic principles of sound scientific methodology (cf. http://www.consort-statement.org) and to general and field-specific guidelines on authorship could help curb problems, such as publishing misconduct, primarily plagiarism, conflict of interest, duplicate publications, and ghost and guest authorship. In that respect, the European Association of Science Editors guidelines (2011), now translated into 19 languages, could be mentioned in the journals' own 'instructions for authors'. 


\subsection{Internationalization: the role of English in the upgrading of peripheral scholarly journals}

To cross national boundaries and embark on the ship of internationalization, a series of additional measures could be undertaken. Peripheral journals could be multilingual (bilingual or even trilingual) and publish papers written both in the regional language(s) (e.g. Spanish and Portuguese in Latin America) and in English. Non-English written papers should present some accurate referential information in English in the form of titles, extended abstracts and keywords (Morley \& Kerans, 2013; Salager-Meyer, 2009). This is what Iranian and Chinese journals are increasingly doing (Habibzadeh, 2006a; Shen et al., 2010).

Since non-native English speaking scientists, particularly those on the scientific periphery, often have difficulties writing in English, journals should appoint language service providers specialized in academic writing who would work jointly with experts from various disciplinary fields (Benfield \& Feak, 2006). The problem with journals that provide full-text translations of the articles they publish into English is a difficult one to solve because high-quality specialized translation is very expensive and takes a significant share of a journal's budget (Piccoli \& Procianoy, 2007). One possibility could be to translate into English a few selected papers, such as review/state-of-the-art articles.

As journals of high quality which observe internationally acknowledged peer review procedures and principles of research integrity, these journals would attract the attention of both national and foreign authors since these journals would be bilingual or trilingual. As Kosanović (2013) asserts, when a Serbian journal achieves its goal of being indexed in the Web of Science, authors from other countries start sending their papers to that journal, thereby increasing its international audience. In other words, internationalization of authors, reviewers and editors should be encouraged (Caramelli \& Rocha e Silva, 2010; Gasparyan, Ayvazyan, \& Kitas, 2011; Uysal \& Coker, 2011).

\subsection{Educational issues}

Universities, local learned societies, and journal editors should cooperate and together periodically assess the quality of the journals they publish. Through workshops and seminars, universities should also be responsible for training researchers, journal staff, and editors to become acquainted with the culture of academic publishing and written communication skills (i.e. the basic rules of academic reporting, the process of manuscript preparation, etc.) both in the scholars' L1 and in English. This is all the more important because high-quality translation requires careful editing of the original language version in terms of clarity, consistency, and lack of ambiguity (Morley \& Kerans, 2013).

Moreover, due to the importance of ethical publishing (Greineisen \& Zhang, 2012; Scott-Lichter, 2012), promotion of good research conduct should be taught to authors, reviewers, and editors through seminars, workshops, and/or national/regional congresses so as to raise their general knowledge on publication ethics. In some places, indeed, unethical behavior may be due to cultural differences that lead to different interpretations of ethical issues, such as ghost writing and plagiarism (Habibzadeh \& Marcovitch, 2011). The sooner researchers become aware of such problems, the better. This is why graduate students should be a targeted audience as well. Universities and local professional associations should then design policies to deal with these issues.

Finally, editors, who play a crucial role in the quality of scholarly research and learned publishing, could act as educators or mentors by training novice journal editors and/or researchers and reviewers. Journals could also publish educational materials addressed to their potential contributors and reviewers by adjusting these materials to the needs of specific scientific communities.

\section{Conclusions}

Science is part of culture. It is not done in an ivory tower separated from the rest of society (Meneghini \& Packer, 2007), and it is an essential source of knowledge for economic and technological development. The role of high-quality peripheral journals, which all face huge challenges a decade into the 21 st century, is fundamental in that development. I posit that the journal measures I propose here will allow robust scientific achievements to be published in journals emanating from developing countries and will permit such journals to play a role in the highly competitive publishing environment. The inclusion of peripheral journals in international databases would provide them with more comprehensive coverage, bringing peripheral countries the recognition they deserve for their scholarly contribution. The problem of "lost science" (Stolerman \& Stenius, 2008) would not be an issue any longer because the bi/trilingual presentation of peripheral journals coupled with the presence of extended English abstracts and keywords would allow the international scientific community to be aware of worthwhile peripheral insights and research results.

\section{Conflict of interest}

The funder had no role in the decision to publish or in the preparation of the manuscript.

\section{Acknowledgments}

This research was supported by the University of The Andes Research Center (CDCHTA/ULA), Grant N $\infty$ M-1039-13-06. I would like to thank Maria Kuteeva and Anna Mauranen who read various iterations of the paper and generously offered their perspectives and suggestions. 


\section{References}

Balaram, P. (2013). Open access: tearing down barriers. Current Science, 104(4), 403-404.

Beall, J. (2012). Predatory publishers are corrupting open access. Nature, 489, 179.

Benfield, J., \& Feak, C. (2006). How authors can cope with the burden of English as an international language. Chest, 129, 1728-1730.

Canagarajah, A. S. (1996). Non-discursive requirements in academic publishing, material resources of periphery scholars, and the politics of knowledge production. Written Communication, 13(4), 435-472.

Canagarajah, A. S. (2002). A geopolitics of academic writing. Pittsburgh: University of Pittsburgh Press.

Caramelli, B., \& Rocha e Silva, M. (2010). Brazilian medical journals are now facing a big challenge. European Science Editing, 36(2), 38-39.

Coates, R. B., Sturgeon, B., Bohannan, J., \& Pasini, E. (2002). Language and publication in cardiovascular research articles. Cardiovascular Research, 53(2), $279-285$.

Curry, M. J., \& Lillis, T. (2004). Multilingual scholars and the imperative to publish in English: negotiating interests, demands, and rewards. TESOL Quarterly, $38,666-686$.

Davis, Ch. H., \& Eisemon, T. O. (1989). Mainstream and non mainstream scientific literature in four peripheral Asian scientific communities. Scientometrics, $15(3-4), 215-239$.

Duszak, A. (2006). Looking globally, seeing locally: exploring some myths of globalization in academia. Revista Canaria de Estudios Ingleses, 53, $35-45$.

EASE guidelines for authors and translators of scientific articles to be published in English(2011). Available at http://ease.orguk/pdfguidelines/EASE_GuidelinesJune 2011c.pdf Accessed 17.02.13.

Englander, K. (2011). The globalized world of English scientific publishing: an analytical proposal that situates a multilingual scholar. In G. Pérez Bonilla, \& K. Englander (Eds.), Discourses and identities in context of educational changes: Contributions from the USA and Mexico (pp. 211-230). New York: Peter Lang.

Ferguson, G., Pérez Llantada, C., \& Plo, R. (2011). English as an international language of scientific publication: a study of attitudes. World Englishes, 30(1), $41-59$.

Flowerdew, J. (2013). Some thoughts on English for research publication purposes (ERPP) and related issues. Language Teaching. http://dx.doi.org/10.1017/ S0261444812000523. Available on CJO.

Flowerdew, J., \& Li, Y. (2009). English or Chinese? The trade-off between local and international publication among Chinese academics in the humanities and social sciences. Journal of Second Language Writing, 1, 1-16.

Gasparyan, A. Y., Ayvazyan, L., \& Kitas, G. D. (2011). Biomedical journal editing: elements of success. Croatian Medical Journal, 52(3), 423-428.

Greineisen, M. L., \& Zhang, M. (2012). A comprehensive survey of retracted articles from the scholarly literature. PLOS One, 7(10), e44118. http://dx.doi.org/ 10.1371 /journal.pone.0044118.

Guédon, J. C. (2010). Acesso Aberto e divisão entre ciência predominante e ciência periférica. In S. M. Soares Pinto Ferreira, \& M. Graças Targino (Eds.), Acessibilidade e Visibilidade de Revistas Científicas Eletrônicas (pp. 21-77). São Paulo: Senac. Available in English at http://eprints.rclis.org/12156/ (Open Access and the divide between "mainstream" and "peripheral" science).

Habibzadeh, F. (2006a). A bird' eye view of science publishing and editing in Iran. European Science Editing, 32(4), 98-100.

Habibzadeh, F. (2006b). A snapshot of medical journals from the Middle East. Lancet, $377,978$.

Habibzadeh, F. \& Marcovitch, H. (2011). Plagiarism: the emperor's new clothes. European Science Editing, 37(3), 67-69.

Harzing, A. W. (2013). Document categories in the ISI Web of knowledge: misunderstanding the social sciences? Scientometrics, 94(1), 23-34.

Harzing, A. W., \& Metz, I. (2012). Explaining geographic diversity of editorial boards: the role of conference participation and English-language skills European Journal of International Management, 6(6), 697-715.

Johns, A. (2013). The history of English for specific purposes research. In B. Paltridge, \& S. Starfield (Eds.), Handbook of English for specific purposes (pp. 5-30). John Wiley.

Kosanović, B. (2013). Open access in Serbia: Interview with Bilijana Kosanović. http://poynder.blogspot.com/2013/09/open-access-in-serbia-interview-with. html Accessed 14.10.13.

Li, Y. (2014). Chinese medical doctors negotiating the pressure of the publication requirement. Ibérica (in press).

Li, Y., \& Flowerdew, J. (2009). International engagement versus local commitment: Hong Kong academics in the humanities and social sciences writing for publication. Journal of English for Academic Purposes, 8, 279-293.

Lillis, T., \& Curry, M. J. (2010). Academic writing in a global context: The politics and practices of publishing in English. London/New York: Routledge.

Lillis, T., \& Curry, M. J. (2013). English, scientific publishing and participation in the global knowledge economy. In E. Erling, \& P. Sargeant (Eds.), English and international development (pp. 220-242). Clevedon, UK: Multilingual Matters.

Lown, B., \& Banerjee, A. (2006). The developing world in the New England Journal of Medicine. Globalization and Health, 2(3). Available from http://www. globalizationandhealth.com/content/2/1/3 Accessed 05.08.13.

Martínez, I. (2011). Capitalizing on the advantage of the Latin American EAP situation: using authentic and specific materials in EAP writing instruction. Ibérica, 21, 31-48.

Meneghini, R., \& Packer, A. L. (2007). Is there science beyond English? Initiatives to increase the quality and visibility of $\mathrm{n}$ on-English publications might help to break down the language barriers in scientific communication. EMBO (European Molecular Biology Organization) Reports, 8, 112-116.

Morley, G., \& Kerans, M. E. (2013). Bilingual publication of academic journals: motivations and practicalities. In V. Matarese (Ed.), Supporting research writing. Roles and challenges in multilingual settings. Witney, Oxford UK: Chandos.

Mur Dueñas, P. (2012). Getting research published internationally in English: an ethnographic account of a team of Finance Spanish scholars' struggles. Ibérica, 24, 139-156.

Petersen, M., \& Shaw, P. (2002). Language and disciplinary difference in a biliterate context. World Englishes, 21, 257-375.

Piccoli, N. B., \& Procianoy, R. (2007). Brazilian scientific journals: an overview. European Science Editing, 33(3), 73-76.

Salager-Meyer, F. (2008). Scientific publishing in developing countries: challenges for the future. Journal of English for Academic Purposes, 7, $121-132$.

Salager-Meyer, F. (2009). Academic equality and cooperative justice. Teachers of English to Speakers of Other Languages Quarterly, 43(4), 703-709.

Scott-Lichter, D. (2012). Authorship disputes: me first, me equally, me too, not me. Learned Publishing, 25(2), 83-85.

Shashok, K. (2008). Content and communication: how can peer review provide helpful feedback about the writing? BMC Medical Research Methodology, 8(3). www.biomedcentral.com/bmcmedresmethodol/archive/ Accessed 14.07.13.

Shen, M., Jiang, W. J., \& Zheng, S. S. (2010). China's medical periodicals: from localization to internationalization. Learned Publishing, $23,303-311$.

Stegemann, H. (2007). Raising the visibility of "small journals": the Venezuelan Association of Biomedical Journal Editors (ASEREME). The Write Stuff, 16(4), $161-165$.

Stolerman, I. P., \& Stenius, K. (2008). The language barrier and institutional provincialism in science. Drug Alcohol Dependence, 92, 3-8.

The Royal Society. (2011). Knowledge, networks and nations: Global scientific collaboration in the 21st century. London: The Royal Society.

Uysal, S., \& Coker, C. (2011). Scientific medical journals in Turkey: current state and goals. European Science Editing, 37(4), 109-111.

Uzuner, S. (2008). Multilingual scholars' participation in core/global academic communities: a literature review. Journal of English for Academic Purposes, 7 , $250-263$.

Yanos, P. T., \& Ziedonis, D. M. (2006). The patient-oriented clinician-researcher: advantages and challenges of being a double agent. Psychiatric Services, 57(2), 249-253. 